\title{
Multiple Carboxylase Deficiency Organic Acidemia as a Cause of Infantile Seizures
}

\author{
Safia Fatima, Muhammad Aamir and Afshan Bibi \\ Department of Chemical Pathology and Endocrinology, Armed Forces Institute of Pathology, Rawalpindi, Pakistan
}

\begin{abstract}
Multiple carboxylase deficiency organic Acidemia is a rare inherited metabolic disorder. It is autosomal recessive disorder of two types: Holocarboxylase deficiency and Biotinidase deficiency. It is the metabolic disorder resulting from deficiency of biotin as a co-enzyme or reduced activity of biotin-dependent carboxylases (propionyl CoA carboxylase, and 3-methylcrotonyl CoA carboxylase and pyruvate carboxylase). A case of two months' female child is reported, who presented with recurrent infantile seizures and skin rash since birth; and biochemically with metabolic acidosis, hyper-ammonemia (on and off) since birth with multiple hospitalization. She had past history of jaundice. One sibling's death at $2^{\text {nd }}$ day of life due to similar complaints. Initial presentation of raised ammonia and lactate levels were the first indication to this organic academia, which was later proven by increased peak levels of various organic acids on urine organic acid analysis by gas chromatography-mass spectrometry.
\end{abstract}

Key Words: Multiple carboxylase deficiency, Holocarboxylase synthetase deficiency, Biotinidase deficiency.

How to cite this article: Fatima S, Aamir M, Bibi A. Multiple Carboxylase Deficiency Organic Acidemia as a Cause of Infantile Seizures. J Coll Physicians Surg Pak 2021; 31(01):95-97.

\section{INTRODUCTION}

Multiple carboxylase deficiency (MCD) organic Acidemia is an inherited metabolic disorder due to dysfunction of multiplebiotin-dependent enzymes. ${ }^{1}$ The USA documented incidence rate is $1: 100,000 .^{2}$ It is autosomal recessive disorder. ${ }^{3}$ There are two types of MCD organic Acidemias: Holocarboxylase deficiency and Biotinidase deficiency. Holocarboxylase synthetase deficiency occurs by mutations in the HLCS gene (21q22.1). Biotinidase deficiency is caused by mutations in the BTD gene ${ }^{4}$ leading to defective activity of propionyl CoA carboxylase, 3-methylcrotonyl CoA carboxylase, and pyruvate carboxylase. Their deficiencies cause marked elevation of 3 hydroxy-propionate, 3 hydroxy butyrate, 3 methyl crotonyl glycine, tiglyl glycine, methyl citrate, and lactate in urine. However, holocarboxylase deficiency presents in early neonatal life. Biotinidase deficiency has comparatively late onset. These disorders collectively present with difficulty in feeding, breathing difficulties, myopathy, lethargy, seizures, skin rash, alopecia, and developmental delay; and "tomcat urine" smell is characteristic. ${ }^{5}$

Correspondence to: Dr. Safia Fatima, Department of Chemical Pathology and Endocrinology, AFIP, National University of Medical Sciences, Rawalpindi, Pakistan E-mail: sofy_asim@hotmail.com

Received: May 03, 2019; Revised: January 02, 2020;

Accepted: July 06, 2020

DOI: https://doi.org/10.29271/jcpsp.2021.01.95
Analysis of urine organic acids on gas chromatography mass spectrometry (GC-MS) is a key test in the assessment of patients with this disorder. Both groups respond dramatically to biotin therapy with excellent prognosis. As it is a rare disorder, and not reported so far in Pakistan, a case is being presented after informed consent taken from child's parents in order to create awareness in ourpopulation for this disorder.

\section{CASE REPORT}

A two months' female child resident of Khushab was brought by her parents to the Pediatric Metabolic Department of Armed Forced Institute of Pathology (AFIP), Rawalpindi, for evaluation of inborn error of metabolism with complaints of persistent infantile seizures of one week's duration. She was admitted in Military Hospital (MH), Rawalpindi with history of infantile seizures for the last one week. Her seizures were initially limited to the left leg but then progressed to right leg and further involved the whole body. Seizures were associated with mouth frothing. There was a time period of approximately 15 minutes between two successive seizures and there were no other associated complaints. According to parents, she was born at full-term by normal delivery at private clinic. She was breast fed up till now. She developed jaundice on $4^{\text {th }}$ day of birth, for which she was given phototherapy for three days. It resolved completely after one month. On $12^{\text {th }}$ day of birth, patient developed generalized skin rash which was settled after one week with flu, but there was no associated fever. Parents also used some herbal treatment for the rash. The child was being vaccinated as per EPI schedule. She belongs to lower socioeconomic class. Her parents had consanguineous 
marriage with two children. One of her brother died at the age of 9 years due to unknown disease, with strong suspicion of some inherited metabolic disease. On general physical examination, pulse was 110/ min (regular), respiratory rate 22/min, no fever, weight $5.0 \mathrm{Kgs}\left(50^{\text {th }}\right.$ percentile), length, $53 \mathrm{~cm}\left(<10^{\text {th }}\right.$ percentile) with no pallor, jaundice, and cyanosis. Systemic examination did not reveal any significant abnormality. On laboratory investigations, herblood complete picture showed hemoglobin (Hb), 9.6 (12.0-15.0g/dl), total leucocyte count (TLC), $12.3 \times 10$ 9/L (normal range: $4.0-11.0$ ) $\times 10^{9} / \mathrm{L}$, platelet count, 910 (normal range $150-400 \times 10^{9} / \mathrm{L}$ ) and random plasma glucose, $98 \mathrm{mg} / \mathrm{dl}$. Renal function tests showed urea $3.5 \mathrm{mmol} / \mathrm{L}$ (normal range 2.3 - 6.7), creatinine $45 \mu \mathrm{mol} / \mathrm{L}$ (normal range 27- 65), sodium, $137 \mathrm{mmol} / \mathrm{L}$ (normal range 136 - 149) and potassium $4.8 \mathrm{mmol} / \mathrm{L}$ (normal range 3.5-5.0). Liver function tests revealed alanine aminotransferase (ALT) $19 \mathrm{U} / \mathrm{L}$ (up to 42), albumin, 33g/L (normal range 35-50), total bilirubin, 5.13 $\mu \mathrm{mol} / \mathrm{L}$ (normal range 0-17), and alkaline phosphatase (ALP) $201 \mathrm{U} / \mathrm{L}$ (normal range 54-500). Inherited metabolic diseases screening revealed raised plasma ammonia, $69.0 \mu \mathrm{mol} / \mathrm{L}$ (normal range 12-47) and plasma lactate was $10.1 \mathrm{mmol} / \mathrm{L}$ (normal range 0.5-2.22), while urine for ketone bodies, reducing substances and colorimetric metabolic screening were negative. The plasma aminoacid profile by high-performance liquid chromatography (HPLC) bichrome does not indicate any aminoacidopathies. Urine organic acids was done on GC-MS which showed elevated peak of 3-hydroxy butyrate, 145 (reference value $<8$ umol/mmol of creatinine) with $96 \%$ probability, moderate elevation of 3-hydroxy propionate, 56 (reference value $<12 \mathrm{umol} / \mathrm{mmol}$ of creatinine) with $87 \%$ probability, 2-hydroxy isovalerate, 28 (reference value $<6 \mathrm{umol} / \mathrm{mmol}$ of creatinine) with $94 \%$ probability and elevated peaks of lactate and pyruvate as shown in Figure 1, thus giving the diagnosis of Mixed Carboxylases Deficiency. It was also supported by clinical manifestations and normal non-contrast enhanced CT brain findings.

Family was counselled about the disease, its good prognosis after biotin supplementation, and neural complications due to the disease, if not treated promptly. The aim of the nutritional supplementation was to prevent central nervous system complications.

The child showed poor response to nutritional supplementation up till now. Six-monthly follow-up was advised for evaluating improvement in her developmental growth with dietary modification.

\section{DISCUSSION}

Our case was first ever diagnosed at AFIP, pediatric metabolic laboratory in the sense that it had central nervous system abnormalities (seizures) with biochemical evidence of elevated ammonia, lactate. Confirmed by urine organic acids analysis, which showed elevated peaks of 3-hydroxy butyrate, 3-hydroxy propionate and 3-hydroxy isovalerate, lactate and pyruvate. MCD is a complex type of organic academia due to deficiency of biotinidase, an enzyme which requires biotin as a cofactor, thus leading to deficiencies of multiple carboxylases. ${ }^{6}$ Due to block of intermediary processes, there is accumulation of different toxic organic acids, which are detrimental to central nervous tissue and leads to developmental delay and seizures. The laboratory findings which were seen in our patient, i.e., marked elevation of different organic acids, are similar to previous studies carried out in Iran and India. ${ }^{7-8}$

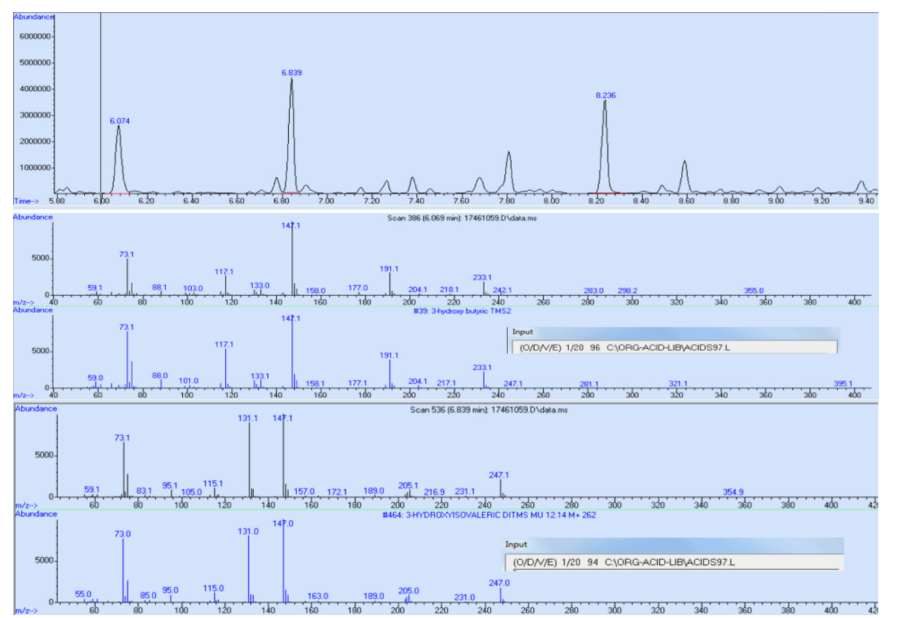

Figure 1: Gas chromatography-mass spectrometry (GC-MS)'s chromatograms of patient showing multiple significant peaks of organic acid identified with their respective probabilities from GC-MS library: 3-hydroxy butyrate, 3-hydroxyisovaleric acid and 3-hydroxy propionic acid with $96 \%, 94 \%$ and $87 \%$ probabilities, respectively.

Protein restriction is the main dietary therapy for patients who were diagnosed with an organic aciduria because even the little amount of protein, these children eat lead to generation of harmful organic acids which would be detrimental for their mental growth. Emergency treatment in the form of glucose drip should be provided when organic acids levels are high. The lactic acidosis due to this organic academia is mostly difficult to treat with oral bicarbonate and citrate supplements, but studies showed that this lactic acidosis responds quickly to 10 mg daily biotin. ${ }^{9-10}$ The long term supportive treatment (supplementation with carnitine, glycine and biotin) was aimed to reduce urine organic acids levels, close to normal reference along with maintenance of normal growth velocity, reduction in acute seizures and neurological abnormalities. The developmental and intellectual delay can be prevented if biotin can be provided early in life of children with this disorder. ${ }^{11}$

Fresh urine samples were immediately processed in order to prevent loss of these metabolites due to delayed handling. We ruled out other inherited metabolic diseases in our patient by the complete plasma amino acids analysis and other types of important organic Acidemias. Enzymatic confirmation of the diagnosis of MCD should be done by biotinidase enzyme activity measurement as a new born screening which is very sensitive for biotinidase deficiency or mutation analysis. ${ }^{12}$ This disease should be monitored by an experienced interdisciplinary team, with proper counselling, parental education and nutritional supplementation. 


\section{PATIENT'S CONSENT:}

Informed consent was obtained from the patient's parents for publishing the data concerning this case and mentioned in case report.

\section{CONFLICT OF INTEREST:}

The author declared no conflict of interest.

\section{AUTHORS' CONTRIBUTION:}

SF: Did planning, data collection, analysis and manuscript writing.

MA, AB: Revised the manuscript.

\section{REFERENCES}

1. Vaidyanathan K, Narayanan MP, Vasudevan DM. Organic acidurias: An updated review. Indian J Clin Biochem 2011; 26(4):319-25. doi: 10.1007/s12291-011-0134-2.

2. Wolf $B$. Clinical issues and frequent questions about biotinidase deficiency. Mol Genet Metab 2010; 100(1): 6-13. doi: 10.1016/j.ymgme.2010.01.003.

3. Cowan TM, Kazerouni NN, Dharajiya N, Lorey F, Roberson $M$, Hodgkinson $C$, et al. Increased incidence of profound biotinidase deficiency among hispanic newborns in California. Mol Genet Metab 2012; 106(4):485-7. doi: 10.1016/j.ymgme.2012.05.017

4. Pindolia KS, Jordan M, Wolf B. Analysis of mutations causing biotinidase deficiency. Hum Mutat 2010; 31(9):983-91. doi: 10.1002/humu.21303.
5. Wolf B. Biotinidase deficiency should be considered in individuals exhibiting myelopathy with or without and vision loss. Mol Genet Metab 2015; 116(3):113-8. doi: 10.1016/j.ymgme.2015.08.012.

6. Wolf B. Biotinidase deficiency: If you have to have an inherited metabolic disease, this is the one to have. Genet Med 2012; 14(6):565-75. doi: 10.1038/gim.2011.6.

7. Keyfi F, Lukacs Z, Varasteh. A description of reference ranges for organic acids in urine samples from a pediatric population in Iran. Rep Biochem Mol Biol 2017; 6(1):40-50.

8. Kumari C, Singh A, Ramji S, Shoemaker JD, Kapoor S. Urinary organic acids quantitated in a healthy North Indian pediatric population. Indian J Clin Biochem 2014; 30(2):221-9. doi: 10.1007/s12291-014-0419-3.

9. Chapman Kimberly A. Practical management of organic acidemias. Transl Sci Rare Dis 2019; 4(3-4): 121-131. doi:10.3233/trd-190039.

10. Saudubray JM, Baumgartner M, Walter J. Inborn Metabolic Diseases: Diagnosis and Treatment. Germany: Springer; 2016.

11. Küry S, Ramaekers V, Bézieau S, Wolf B. Clinical utility gene card for: Biotinidase deficiency. Eur J Hum Genet 2016; 24(7). doi: 10.1038/ejhg.2015.246.

12. Villani GR, Gallo G, Scolamiero E, Salvatore F, Ruoppolo M. "Classical organic acidurias": diagnosis and pathogenesis. Clin Exp Med. 2017; 17(3):305-323. doi: 10.1007/ s10238016-0435-0. 